\title{
Diurnal Variations of Total Ozone Over Kathmandu Measured by Brewer Spectrophotometer
}

\author{
Narayan Prasad Chapagain \\ Department of Physics, Patan Multipal Campus \\ Tribhuvan University, Kathmandu, Nepal \\ Email:npchapagain@gmail.com
}

\begin{abstract}
This study presents the diurnal variations of atmospheric total ozone (or ozone content) measurements over Kirtipur, Kathmandu $\left(27.67^{\circ} \mathrm{N}, 83.295^{\circ} \mathrm{E}\right)$ using a Brewer Spectrophotometer during a one-year period from February 2001 to February 2002. The measurements of ozone content were made only on daytime period. Result illustrates the significant diurnal variations of total ozone with maximum at near noon and minimum in the early morning and evening hours. The observed increase in total ozone around the noontime is about 5-10\% of average ozone value. The monthly averages of total ozone for corresponding times are estimated from the selective days of good data set throughout the measurement period and then the seasonal averages of ozone for corresponding times are determined. The result clearly reveals seasonal diurnal variations of the total ozone with maximum averages values of ozone in spring and summer seasons and moderate in autumn, while minimum value in winter season.
\end{abstract}

Keywords: Total ozone, Stratosphere, Brewer spectrophotometer, Ozone depletion, Ozone hole

\section{INTRODUCTION}

Most important feature of the middle atmosphere of Earth is the absorption of harmful solar ultraviolet radiation (UV) in the wavelength range of 200-400 nm by ozone. Ozone is a form of triatomic oxygen $\left(\mathrm{O}_{3}\right)$ found mostly in between 10 and $50 \mathrm{~km}$ altitudes, which provides the major source of heating of atmosphere in this region, the so-called stratosphere. It is the primary driving force for most of the atmospheric motions in this region. Although ozone is found in only about one molecule out of every 1,00,000 air molecules, it acts as a valuable protective umbrella for the living organism on Earth [Madronich, 1992]. Absorption of solar UV radiation by ozone also has great significant for the biosphere since the UVB radiation (wavelength range of 280-320 nm), which is mostly absorbed by ozone, has a deleterious effects on plant and animal life on Earth [Frederick et al., 1993]. This important feature has also enabled ozone to paly a significant role in the evolution of early life forms on Earth. Because of these reasons, stratospheric chemistry is centered around ozone, which contributes for the production and destruction of ozone resulting the short- and long-term variations of total ozone on Earth's atmosphere.
The stratospheric ozone is destroying primarily by the chemical pollutants. The main culprits of this destruction are chlorofluorocarbons (CFCs). The chlorine atoms generated from CFCs destroy the ozone molecules in a series of complex reactions resulting the stratospheric ozone depletion. Therefore, the depletion of stratospheric ozone and subsequent increase in UV radiation is a problem of global proportions [Bojkov et al., 1990]. Since UVB radiation can damage to biological systems, there is widespread concern that ozone depletion might be accompanied by numerous adverse impacts to both ecology and human health [WMO, 1988; Bairs et al., 1994].

The concentration of ozone on Earth's atmosphere shows considerable variability, on both a seasonal and latitudinalbasis. Unusually low levels of ozone, however, have been recorded during the past four decades over Antarctica during October and November of each year, and there are indications that similar chemical reactions leading to a decrease in ozone levels may also occur in both the southern and northern hemispheres, but with less severity [Lubin and Hansen, 1995]. It is believed that the injections of anthropogenic compounds into the stratosphere, particularly chlorofluorocarbons (CFCS), 
are responsible for this seasonal loss of ozone.

In the past few decades, the issue of stratospheric chemistry has been key developments. The identification in the early seventies of the possibility of long-term global ozone depletion is mainly due to catalytic reactions in the stratosphere involving chemicals released mostly by anthropogenic activities and its possible impacts on the biosphere by virtue of increased UVB radiation as well as the perturbation in the middle atmospheric radiation budget [Brewer and Kerr, 1973; Basher, 1982; Frederick et al., 1993]. Consequently, the study of ozone variability becomes the great interest of Aeronomy and Atmospheric Science research over the past few decades. Furthermore, the discovery of the Antarctic Ozone Hole in mid-eighties highlighted the gravity of the problem. This was responsible not only for triggering intense scientific research but also discussions and deliberations at the government level, for example, Montreal Protocol, which has far reaching socioeconomic implications [Subbaraya and Lal, 1999].

In Nepal, a few studies have been carried out during the past few years using the ground- and space-based observations. Chapagain [2003] has first reported the variability of atmospheric total ozone over Kathmandu measured by a Brewer Spectrophotometer and compared with Total Ozone Mapping Spectrometer (TOMS) satellite data. The results reported that the total atmospheric ozone over Kathmandu existed low in winter and large in summer and spring seasons. Here total ozone signifies the columnar ozone measurements from surface of the Earth to the stratospheric region. Furthermore, Hamal [2011] analyzed total ozone data measured by Brewer Spectrophotometer and satellite data and illustrated the seasonal variations of columnar ozone over Kathmandu. For the long-term study of the ozone over Nepal, Pokharel [2013] used 9-year of ozone data from TOMS satellite and found the regional and altitudinal variations of columnar ozone. However, the detail analysis of diurnal variation of ozone over Kathmandu has not been reported. In this study, we present the diurnal variations of total ozone in day-to-day and seasonal-wise over Kathmandu using ozone data measured by the Brewer Spectrophotometer installed at Kirtipur, Kathmandu.

\section{DATA MEASUREMENTS}

Data used in this study were obtained from the ozone measurements using Brewer Spectrophotometer deployed at the Central Department of Physics, Tribhuvan University, Kirtipur, Kathmandu, Nepal $\left(27.67^{\circ} \mathrm{N}, 83.295^{\circ} \mathrm{E}\right)$ since January 2000. The Brewer Spectrophotometer is an optical instrument designed to measure ground-level intensities of the attenuated solar UV radiation at five specific wavelengths in the absorption spectra of ozone and sulphur dioxide. By examining the differential absorption of selected wavelengths in the UVB portion of the spectrum, total column ozone is determined. The Brewer is automatically set to the proper observation configuration, and then follows a user-defined observation schedule and data is stored and analyzed. A right-angle zenith prism directs incoming radiation from the sun, the sky, or the test lamps onto the optical axis of the instrument. For zenith angles in the range $0^{\circ}$ to $90^{\circ}$ the sun, or sky, is viewed through an inclined quartz window. Variations in the amount of ozone will affect the radiance of the direct solar radiation at these wavelengths (Wayne, 2000). Therefore, UVB radiations as well as total ozone in a vertical column of unit cross- sections are measured systematically with a Brewer Spectrophotometer.

A special feature of the Brewer instrument is its ability for high time resolution. In principle, total ozone measurements can be made at time intervals of every 2 minutes [Chapagain, 2003]. This enables a study of short-term variation in total ozone, especially study of its diurnal variation. The data recorded by Brewer instrument are direct sun (DS) ozone measurements and zenith sky (ZS) ozone measurements. The measurements are in Dobson Units (DU). In this study, we use data for one-year period during February 2001 February 2002. To study the day-to-day diurnal variations of the total ozone, the data presented in this paper are only for a representative days selected from several observations, while for the seasonal study of diurnal variations of total ozone, we have used all data set from one-year-period to estimate the average value of ozone for the corresponding times on each season. 


\section{RESULTS AND DISCUSSION}

\subsection{Diurnal Variations of Total Ozone}

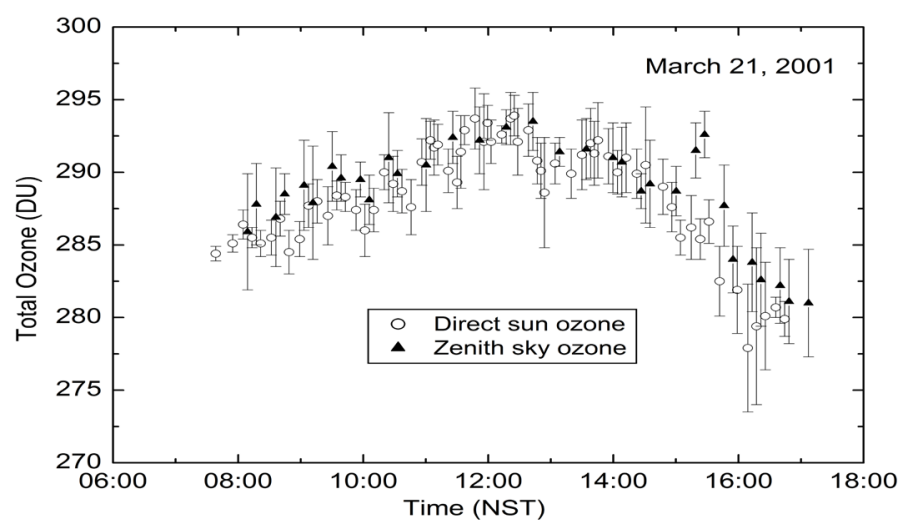

Figure 1. Diurnal variations of total ozone over Kathmandu on March 21, 2001 measured at direct sun ozone and zenith sky ozone observations.

The Brewer direct sun ozone data and zenith sky ozone data over Kathmandu on March 21, 2001 are plotted with respect to Nepali Standard Time (NST) in hours as shown in Figure 1. The vertical bars show the error in the measurements of total ozone. The pattern of change of total ozone exhibits similar behavior in direct sun and zenith sky ozone measurements. The results show that amount of total ozone from both direct sun ozone and zenith sky ozone measurements over Kathmandu increase from early morning hour as day progresses and become maximum up to $295 \mathrm{DU}$ around local noon. Then the total ozone values decrease gradually with time in afternoon period and fall to minimum value around $280 \mathrm{DU}$ in evening hour.

For the comparison of these two types of measurements, we plotted the direct sun ozone data versus zenith sky ozone data on March 21, 2001 as shown in Figure 2. The result clearly shows that two data sets are significantly correlated as shown by the linear fit with the correlation coefficient of 0.90. Hence for further detail analysis of the ozone data, the direct sun ozone measurements are taken.

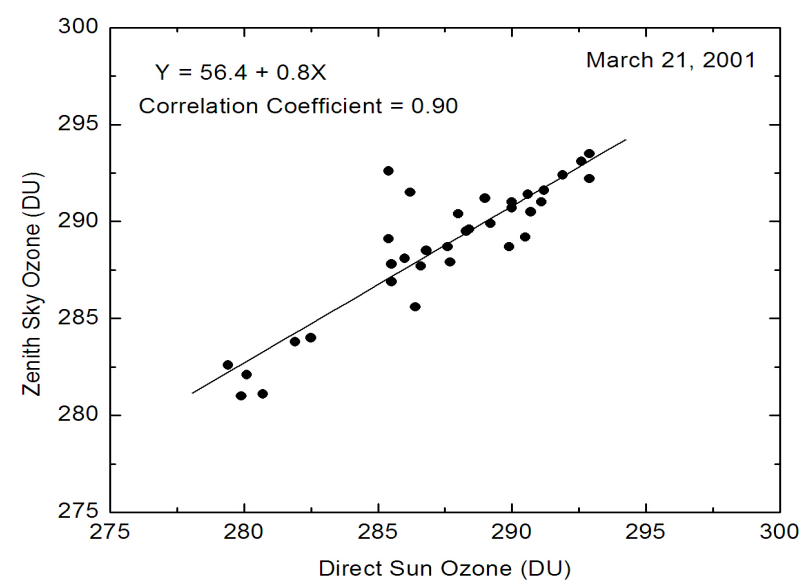

Figure 2. Comparison of direct sun ozone measurements with zenith sky measurements of total ozone over Kathmandu on March 21, 2001.

Figure 3 plots the total ozone data as a function of Nepali Standard Time (NST) over Kathmandu from the typical days form February 2001 to February 2002, selected from different months. From the plot on February 22, 2001, the ozone values vary from about $255 \mathrm{DU}$ to $280 \mathrm{DU}$, while on April 30, 2001, range of ozone variations exhibits from 285 to 310 DU. Similarly, plots on May 23 and June 1, 2001, illustrates that the minimum value of total ozone is $275 \mathrm{DU}$ at early morning ( 07:00) and early evening hours ( 17:00 NST), while the maximum value exhibits about 300 DU near local noon. The amplitude of diurnal variation is up to 25 DU with average value of total ozone 290 DU. The results from other days plotted in Figure 3 also show maximum values of total ozone at near noon $(\sim 11: 00-13: 00$ NST) and clear minima in the morning around $\sim 06: 00-07: 00$ NST and in the early evening hour after $\sim 15: 00$ NST during the measurements period in cloud free days. The amplitudes of diurnal variations are large on April 30, May 23, and June 11 (i.e. up to $25 \mathrm{DU}$ ), while these values exist small on February 22, November 1, and December 1, 2001 and February 23, 2002 (i.e. amplitude of about 10 DU). The study shows that the diurnal variation is significantly large in spring and summer days (e.g. April, May, June) with higher average values, while the ozone values are low with small fluctuations in winter days (December and February). 

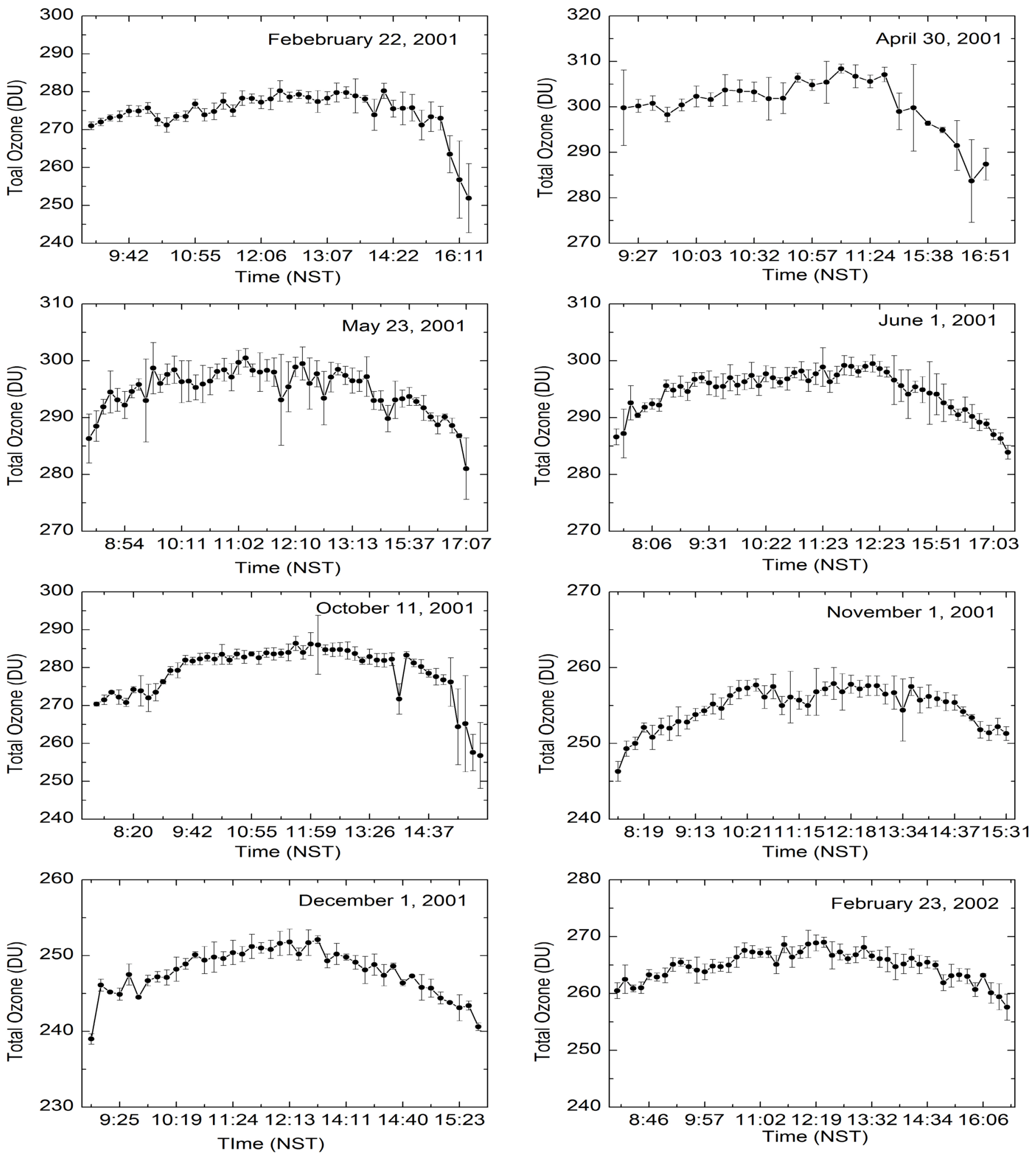

Figure 3. Diurnal variations of total ozone over Kathmandu on selected 8 days from different months. Ozone data are measured in Dobson unit (DU) while the time is plotted in Nepali Standard Time (NST). Vertical bars denote the errors in the measurements of total ozone. 
The amplitude of diurnal variation is asymmetric. The result presented in this study covers only for the daytime observations, as we don't have measurements during the nighttime period. The ozone concentration increases in the noontime, as the photochemical reactions are significantly higher due to the increase in solar flux intensity in the atmosphere. As a result, the ozone production rates are relatively higher than the ozone destruction rates near noontime causing high concentration of total atmospheric ozone. On the other hand, early morning and evening hours, the solar intensity is weak, resulting the slow photochemical reactions for ozone production, consequently, the ozone concentration becomes minimum.

\subsection{Average Diurnal Variations of Total Ozone}

For the detail analysis of the diurnal variations of total ozone on different seasons, we have estimated average total ozone values for the corresponding times of the days from four seasons: spring (March, April and May), summer (June, July and August), autumn (September, October and November), and winter (December, January and February). Figure 4 plots the comparison of diurnal variations of total ozone in these four seasons. The variation of average total ozone in spring season is 275 to $300 \mathrm{DU}$ with amplitude up to 25 DU. Similarly, the variations of average total ozone are $\sim 270$ to 290 DU in summer, $\sim 250$ to 270 DU in autumn, and $\sim 248$ to 263 DU in winter seasons respectively. The ozone values exist maximum at around noon and just right afternoon hours and minimum at early morning and evening hours as illustrated in Figure 4. The results show that the amplitude of average diurnal variations exhibits large in spring season (with amplitude of $\sim 25 \mathrm{DU}$ ) and small in winter season (with amplitude of $\sim 15 \mathrm{DU}$ ). The amplitude of average diurnal variation is about $5-10 \%$ in terms of the percentage of the mean. The peak values around the noon do not show the similar feature on all days. The observed peakto-peak changes are well beyond the measurement errors and are believed to be genuine.

The other noticeable features in the data are the base value of total ozone that also changes from day-to-day and season-to-season. The ozone values are largest in spring season and lowest in winter season as illustrated in Figure 4. Hence, the studies of day-to-day as well as seasonal variations of total ozone become noteworthy.

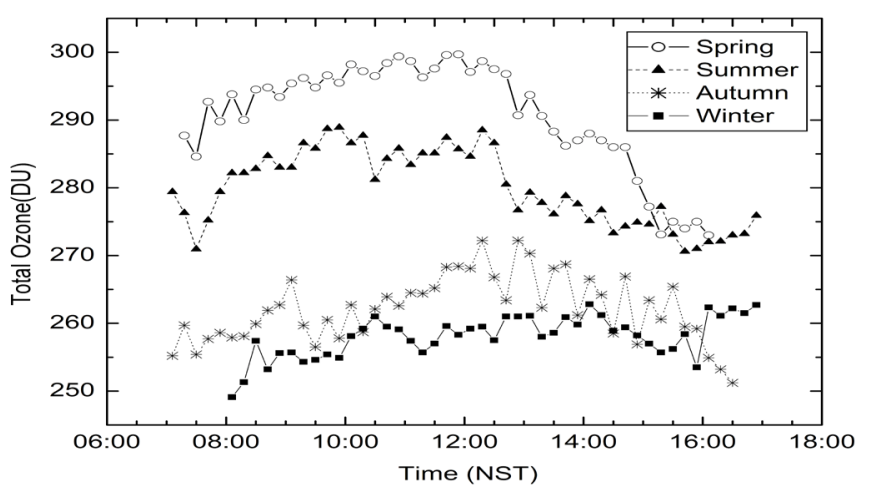

Figure 4. Diurnal variations of average total ozone over Kathmandu during the spring, summer, autumn and winter seasons estimated from one year period from February 2001 to February 2002.

As discussed above, the measurements of total ozone show that the ozone value increases around the noontime. The observed increase in total ozone around noon is much larger effect since almost $90 \%$ of the total overhead ozone is contained in the region below $40 \mathrm{~km}$. At lower altitudes, photochemical life times which are large, become months and years, and one does not expect any short - term changes, except in lower troposphere where the life time of ozone again decreases with decreasing altitude. Currently available tropospheric photochemical models [Crutzen, 1978; Logan et al., 1985] show that the photochemical reactions involving $\mathrm{CH}_{4}, \mathrm{CO}$ and non-methane - hydrocarbons can result in a net production or destruction of ozone depending upon whether the ambient $\mathrm{NO}_{\mathrm{x}}$ levels are high or low. Nitric oxide and volatile compounds are common products of human activities and are released in large quantities basically from vehicle engines and industries. Under suitable meteorological conditions (with almost no vertical exchange and little ventilation), these pollutants tend to accumulate in the boundary layer. Under increased sunlight, they undergo photochemical transformation. Under cloudy sky, ozone production is not as much as during a clear sky. Non-methane hydrocarbons exhausted by automobiles acts as a catalyst in the production of ozone. The critical concentration of $\mathrm{NO}_{x}$, which also acts as a catalyst, is about $10 \mathrm{pptv}$ (parts per trillion by volume) for a typical ozone concentration of $30 \mathrm{ppbv}$ (parts per billion by volume) [Subbaraya et al., 1994; Solarsky, 1992]. Below this concentration, ozone destruction and production occur when the concentration is above the critical value. Ozone precursors (NOx, Hydrocarbons) begin to build up during 
morning rush hours while the abundance of ozone reaches its maximum in the early afternoon. Most measurements near the surface over most of the urban polluted areas generally show a noontime maximum in the surface ozone [Lal and Subbaraya, 2000; Zou, 1996]. Only such an effect cannot contribute to the observed noontime increase in total ozone. Since tropospheric ozone forms about $10 \%$ of total ozone and stratospheric ozone is almost $90 \%$ of total overhead ozone, a combination of the lower tropospheric chemistry with high $\mathrm{NO}_{\mathrm{x}}$ air and upper stratospheric - mesospheric chemistry can result in a net increase of ozone around noon hours. However, there is no observational data of $\mathrm{NO}_{\mathrm{x}}$ levels in the surface and tropospheric air over Kathmandu. The observed increase in total ozone over Kathmandu near noontime indicates that during the period of measurements, photochemical control of ozone extended well below $40 \mathrm{~km}$ and the day night photochemistry induced changes are much more pronounced than model predictions. Alternatively, it could be due to a combination of stratospheric and near tropospheric changes with latter characterized by polluted (high $\mathrm{NO}_{\mathrm{x}}$ ) air.

\section{CONCLUSIONS}

The measurements of total ozone over Kathmandu using Brewer spectrophotometer during the daytime period from February 2001 to February 2002 show that total ozone values increase in around noontime period and exhibit minimum values in early morning and evening hours. The observed increase in total ozone near noontime by $\sim 5-10 \%$ of average value indicates that photochemical control of ozone extended well below $40 \mathrm{~km}$ and the day-night photochemistry induced changes are much more pronounced. The result also reveals seasonal variations of the total ozone over Kathmandu with maximum values in spring, and minimum during the winter period. As a future research work, climatological study of ozone variations over Nepal using long-term data set from both ground- and space-based measurements is highly recommended.

\section{ACKNOWLEDGEMENT}

I am grateful to Prof. Dr. Shekhar Gurung Central Department of Physics, Tribhuvan University for making the data available for this study.

\section{REFERENCES}

1. Bairs, et al. (1994), Solar UVB Measurements With Double and Single Monochromator Brewer Ozone Spectrophotometer, Geophysical Research Letters, 23, no. 8 , pp. $833-836$.

2. Basher, R. E. (1982), Review of the Dobson spectrophotometer and its accuracy, WMO Ozone Rep. 13, World Meteorol. Org., Geneva.

3. Bojkov, R. D., V. E. Fioletov, and S. B. Diaz (1995), The relationship between solar UV irradiance and total ozone from observations over southern Argentina, Geophys. Res. Lett, 22, 1249-1252.

4. Brewer, A. W. and Kerr J. B. (1973), Total ozone measurements in cloudy weather, Pure Appl. Geophys., 106-8, 928-937.

5. Chapagain, N. P. (2003), Total Ozone Measurements Over Kathmandu Using Brewer Spectrophotometer, Thesis, Master of Technology, Andhra University, India.

6. Crutzen, P. J., and Fishman (1978), The bulletin interviews WMO bulletin, 47, no.2.

7. Hamal, S.,(2011), Analysis of Total Ozone Measurement by Brewer and Total Ozone Mapping Spectrometer over the Kathmandu valley and at different places of Nepal, M.Sc. Thesis, Central Department of Physics, T.U. Kathmandu, Nepal.

8. Fioletov, V. E. J. B. Kerr, and D. I. Wardle (1997), The relationship between total ozone and spectral UV irradiance from Brewer observations and its use for derivation of total ozone from UV measurements, Geophys. Res. Lett, 24, 2997-3000.

9. Frederick J. E., P. F. Soulen, S. B. Diaz, I. Smolskaia, C. R. Booth, T. Lucas, and D. Neuschuler (1993), Solar ultraviolet irradiance observed from Southern Argentina: September 1990 to March 1991, J. Geophys. Res., 98, 8891-8897.

10. Lal,S. andB.H.Subbaraya(2000), Ozone Measurements at Ahmedabad, Atmospheric Environment, 34, p. 2713 $-2724$.

11. Logan, J. A. (1985), Tropospheric ozone: seasonal behavior trends and anthropogenic influences, $J$. Geophys., Res. 90 (D6), 1046310482.

12. Lubin, D. and O. Holm-Hansen (1995), Atmospheric Ozone and the Biological Impact of Solar Ultraviolet 
Radiation, Encyclopedia of Environmental Biology,

Vol. 1.

13. Madronich, S. (1992), Implications of recent total ozone measurements for biologically active ultraviolet radiation reaching the Earth's surface, Geophys. Res. Lett., 19, 37-40.

14. Pokharel, M. P. (2013), Mapping of Total Column Ozone Over Nepal, using TOMS Data, M.Sc. Thesis, Department of Physics, Patan Multiple Campus, T.U. Kathmandu, Nepal.

15. Solarski, R. S. (1992), Measured trends in stratospheric ozone, Science, 256, 342 - 349.

16. Subbaraya, B. H. and S. Lal (1994), Journal of Atmospheric and Terrestrial Physics, 56, No.12, 1557 -1561 .

17. Subbaraya, B. H. and S. Lal (1999), Space Research in India: Accomplishments and Prospects, PRL Alumni Association, Ahmedabad, India.

18. Wayne, R. P. (2000), Chemistry of Atmospheres, Oxford University Press.

19. WMO (1988), Report of the International Ozone Trends Panel, Global Ozone Research Monitoring Project Report No. 18, Published NASA, NOAA, FAA and UNEP.

20. Zou, V. (1996), Seasonal Variation and Trends of TOMS Ozone Over Tibet, J. Geophys, Res. 90, 10, 463. 